\title{
Absence of the K303R estrogen receptor $\alpha$ mutation in breast cancer patients exhibiting different responses to aromatase inhibitor anastrozole neoadjuvant treatment
}

\author{
CHIARA GHIMENTI ${ }^{1}$, MAURIZIA MELLO-GRAND ${ }^{1}$, LEA REGOLO $^{2}$, \\ ALBERTO ZAMBELLI $^{3}$ and GIOVANNA CHIORINO ${ }^{1}$ \\ ${ }^{1}$ Cancer Genomics Laboratory, Fondazione 'Edo ed Elvo Tempia Valenta', Biella; \\ Units of ${ }^{2}$ Senology, and ${ }^{3}$ Medical Oncology, IRCCS Fondazione 'Salvatore Maugeri', Pavia, Italy
}

Received August 2, 2010; Accepted September 9, 2010

DOI: $10.3892 /$ etm.2010.151

\begin{abstract}
Aromatase inhibitors, such as anastrozole, are established in the treatment of hormone-dependent breast cancer. However, approximately $20 \%$ of patients treated with anastrozole do not respond, and it remains impossible to accurately predict sensitivity. Thus, novel markers to predict response are required. The K303R estrogen receptor (ER) $\alpha$ mutation confers resistance to tamoxifen treatment. Moreover, K303R-expressing MCF-7 cells, transfected with an aromatase expression vector and stimulated with androstenedione (an aromatase substrate), were found to be resistant to the inhibitory effect of anastrozole. The aim of this study was to verify whether the presence of the $\mathrm{K} 303 \mathrm{R} \mathrm{ER} \alpha$ mutation is associated with response to 3-month neoadjuvant treatment with anastrozole (Arimidex) in a cohort of post-menopausal breast cancer patients. Of 37 patients with $\mathrm{ER}^{+}$tumors, 19 showed a clinical response to anastrozole and 18 were resistant. Biopsies were obtained from tumors responding to the therapy or from non-responding tumors. None carried the $\mathrm{K} 303 \mathrm{R}$ ER $\alpha$ mutation. To our knowledge, this is the first study to search for K303R ER $\alpha$ mutations in tumors clinically responsive or resistant to an aromatase inhibitor. Lack of the mutation leads us to believe that this mutation has in vivo biological significance in only a subset of breast cancers.
\end{abstract}

\section{Introduction}

Estrogens are important regulators of cell growth and differentiation in a variety of tissues, including normal mammary epithelium (1). In addition, estrogens play an important role in breast cancer promotion and progression (2). This is based on observations that tumors regress in response to oophorec-

Correspondence to: Dr Chiara Ghimenti, Cancer Genomics Laboratory, Fondazione 'Edo ed Elvo Tempia Valenta', Via Malta 3, I-13900 Biella, Italy

E-mail: chiara.ghimenti@fondoedotempia.it

Key words: breast cancer, aromatase inhibitors, estrogen receptor mutation tomy or after hormone therapies, such as the anti-estrogen tamoxifen or aromatase inhibitors (AI) that block estrogen biosynthesis in post-menopausal women (3-5).

Estrogens affect cellular processes by binding to their cognate receptors, estrogen receptor (ER) $\alpha$ and $\beta$, which function as transcription factors mediating the mitogenic effects of estrogen. ER $\alpha$ expression in normal breast epithelium is generally low; however, significantly higher expression has been reported in pre-malignant lesions (6), with the majority of breast tumors expressing both receptors $(7,8)$. Since prolonged endogenous estrogen exposure is a potential risk factor for invasive breast cancer (9), overexpression of ER $\alpha$ or the emergence of mutated receptors could be early events in tumor progression (10,11). Fuqua et al (12) identified an $A$ to $G$ somatic mutation at $E R \alpha$ nucleotide 908 (A908G) from several usual ductal hyperplasias (early pre-malignant lesions), resulting in a lysine to arginine transition at residue 303 (K303R). To our knowledge, no other $E R \alpha$ mutation has been identified in more than a few invasive breast cancers (13-17).

The K303R ER $\alpha$ mutation has been found to confer resistance to tamoxifen treatment $(11,18)$. Recently, this mutation was investigated in stably wild-type or K303R ER $\alpha$-overexpressing MCF-7 cells, transfected with an aromatase expression vector, stimulated with androstenedione (an aromatase substrate), with or without the AI anastrozole. Anastrozole treatment decreased androstenedione-stimulated growth of the wild-type cells, whereas K303R-expressing cells were resistant to the inhibitory effect of the drug (19). These findings suggest that, since K303R-mutant cells may escape from growth inhibition when treated with AIs, genetic assays for the mutation might offer a novel predictive marker for hormonal response (19).

The aim of this study was to verify whether the presence of the $\mathrm{K} 303 \mathrm{R} E R \alpha$ mutation is associated with response to 3-month neoadjuvant treatment with anastrozole (Arimidex) in a cohort of post-menopausal breast cancer patients.

\section{Materials and methods}

Patients. All tumor samples and clinical data were collected with approval of the Fondazione 'Salvatore Maugeri' Ethics 
Committee and with the informed consent of the patients. The 37 patients enrolled in this study between July 2004 to November 2007 were post-menopausal and had breast cancer stage T2 or T3, tumor size $>2.5 \mathrm{~cm}$, variable lymph node status and no distant metastasis. All of the tumors were $\mathrm{HER} 2 / \mathrm{neu}^{-}$and $\mathrm{ER}^{+} / \mathrm{PgR}^{+}$, apart from two that were $\mathrm{ER}^{+}$ $\mathrm{PgR}^{-}$(Table I). The patients received neoadjuvant therapy with anastrozole (Arimidex ${ }^{\mathrm{TM}}$; Astra Zeneca) $1 \mathrm{mg} /$ day for 3 months. Clinical response was evaluated by serial tumor clinical examination and mammary ultrasound bidimensional measurements, performed by a single operator (L.R.) before, during and after treatment. Patients with a decrease in tumor volume $\geq 30 \%$, according to RECIST criteria (20), were classified as responders.

Sequence analysis. Total DNA was extracted from 37 formalin-fixed, paraffin-embedded breast cancer biopsies using the High Pure PCR Template Preparation kit (Roche Molecular Biochemicals, Basel, Switzerland), according to the manufacturer's instructions.

SNaPshot primer extension sequencing was performed as described by Herynk et al (11).

For dye-labeled terminator sequencing, all DNA samples were amplified by PCR with primers for an ER $\alpha$ exon 4 fragment (216 bp), including the site of the mutation. Oligonucleotide sequences were PCR-ER $\alpha$ F, 5'-GACCGAA GAGGAGGGAGAAT-3' and PCR-ER $\alpha$ R, 5'-GGAATAGAGT ATCGGGGGCT-3'. PCR was carried out in a reaction volume of $25 \mu \mathrm{l}$, containing $100 \mathrm{ng}$ of genomic DNA, $50 \mathrm{mM} \mathrm{KCl}$, $10 \mathrm{mM}$ Tris-Hcl ( $\mathrm{pH} 8.3$ ), $1.5 \mathrm{mM} \mathrm{MgCl}_{2}, 0.1 \mathrm{ng} / \mu \mathrm{l}$ bovine serum albumin (BSA), $200 \mu \mathrm{M}$ dNTPs, $0.3 \mu \mathrm{M}$ each primer and $0.1 \mathrm{U} / \mu \mathrm{l} \mathrm{Taq}$ polymerase. Amplification consisted of an initial denaturation at $95^{\circ} \mathrm{C}$ for $5 \mathrm{~min}$, followed by 35 cycles of $1 \mathrm{~min}$ at $95^{\circ} \mathrm{C}, 45 \mathrm{sec}$ at $58^{\circ} \mathrm{C}$ and $1 \mathrm{~min}$ at $72^{\circ} \mathrm{C}$, with a final extension at $72^{\circ} \mathrm{C}$ for $7 \mathrm{~min}$.

PCR products were purified by Wizard SV Gel and the PCR Clean-Up System (Promega, Madison, WI, USA) and sequenced using the Big Dye Terminator V3.1 Cycle Sequencing kit and Prism Model 3730XL DNA Analyzer (Applied Biosystems, Foster City, CA, USA).

\section{Results}

Using the response criteria as described in Materials and methods, 19 patients were classified as responders and 18 as non-responders (Table I). Only 1 patient (10050) showed disease progression during the treatment.

K303R mutation analysis. As Herynk et al argued that SNaPshot primer extension sequencing is more sensitive than dye-labeled terminator sequencing for the detection of the $E R \alpha \mathrm{K} 303 \mathrm{R}$ mutation (11), an identical approach on an initial group of 10 DNA samples was attempted. Unfortunately, interpretation of the SNaPshot primer extension sequencing results was very difficult, as a very high background was present (data not shown). We then decided to design a new forward primer for PCR amplification, as the Forward PCR ER $\alpha 1$ (described by Herynk et al) was too near to the site of the mutation for a clear sequencing. Thus, Reverse PCR ER $\alpha 2$ was used (11). All DNAs were amplified by PCR and
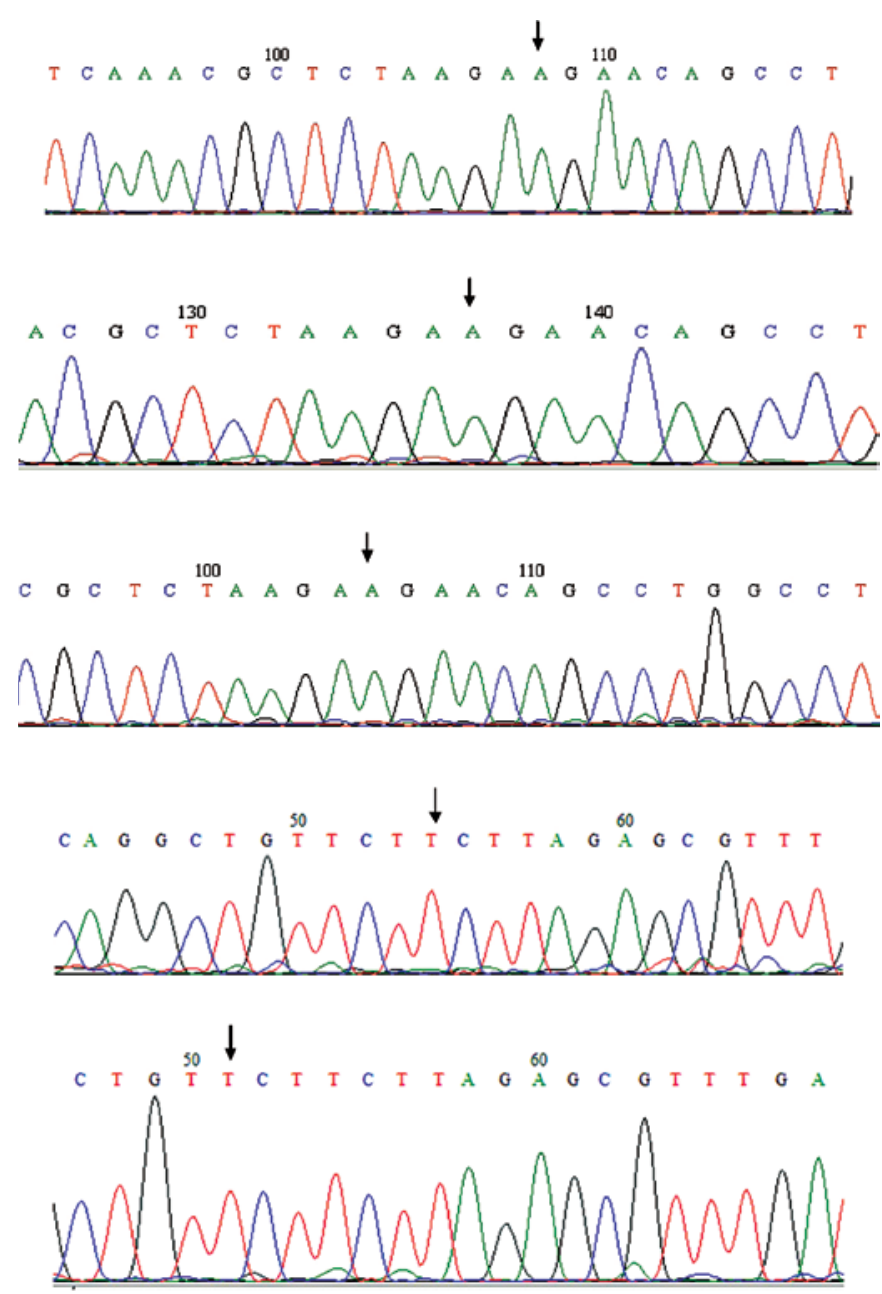

Figure 1. Examples of sequencing of ER $\alpha$ exon 4, as described in Materials and methods. The sequences were shown in forward and reverse orientation; the arrow indicates the wild-type 908 base, A in the forward sequence (TAAGAAGAAC) and $\mathrm{T}$ in the reverse sequence (GTTCTTCTTA).

sequenced as described in Materials and methods. Seven DNA samples showed no suitable PCR product or had no results in sequencing. Forward and reverse sequences were readable for 30 out of the 37 DNA samples, and all showed absence of the K303R mutation. An example of sequencing is shown in Fig. 1.

\section{Discussion}

A somatic mutation at the nucleotide 908 of $E R \alpha$ (A908G) has been identified in pre-malignant breast lesions and invasive breast cancers $(11,12)$. This mutation, resulting in a lysine to arginine transition at residue 303 (K303R), confers hypersensitivity to estrogen and resistance to tamoxifen $(11,18,21)$. Giordano et al hypothesized that the mutant K303R ER $\alpha$ provides a proliferative advantage to breast tissue through a continuous mitogenic stimulus, even during phases of low circulating hormone (as menopause) and demonstrated that its expression conferred resistance to the aromatase inhibitor anastrozole in vitro (19).

The present study is the first to investigate K303R ER $\alpha$ mutations in a cohort of post-menopausal breast cancer patients treated with anastrozole neoadjuvant therapy. The 


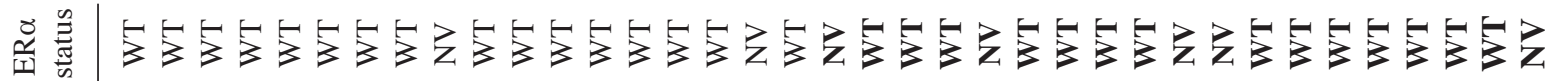

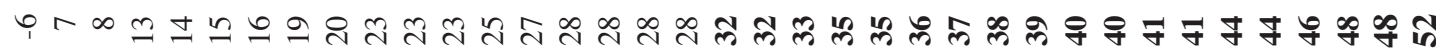

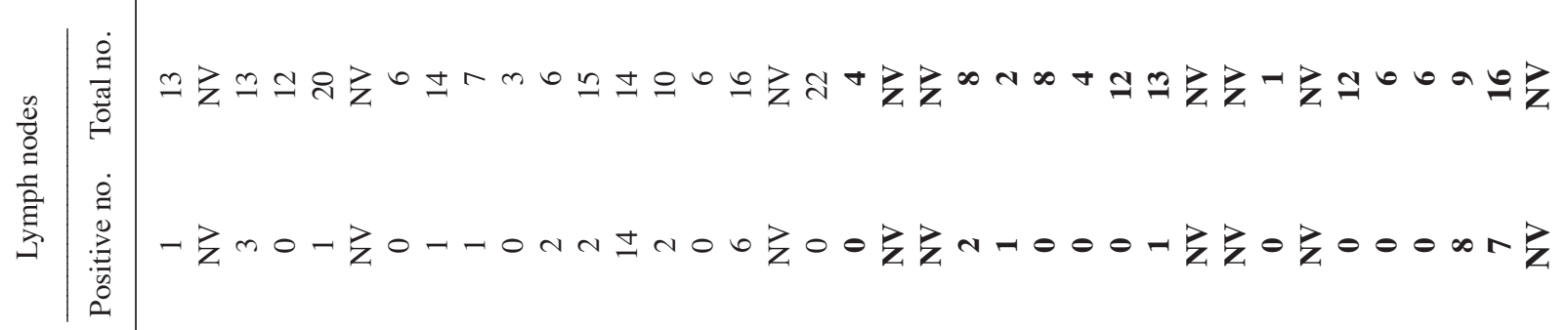

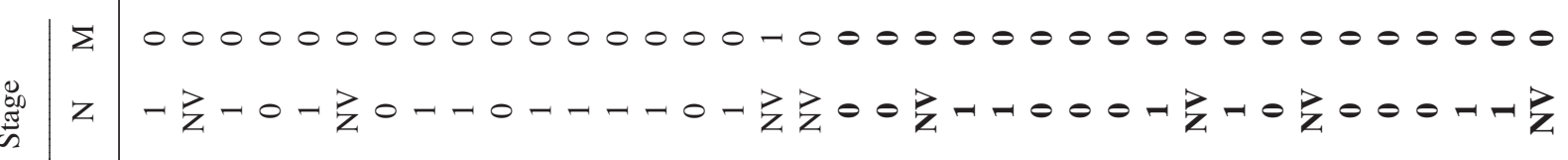

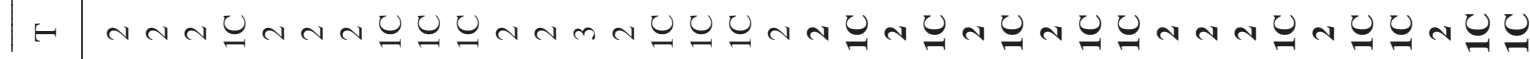

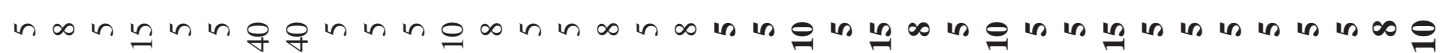

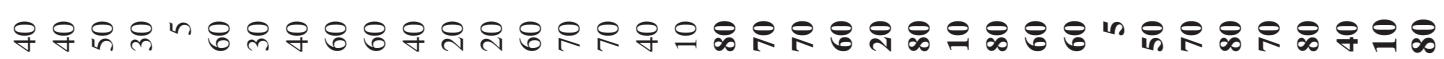

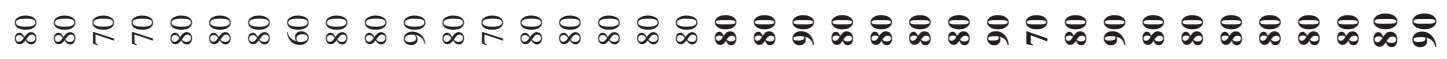

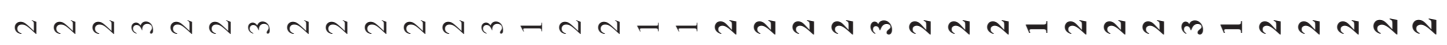

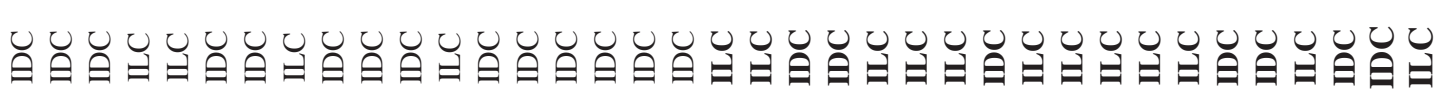
๓ 零

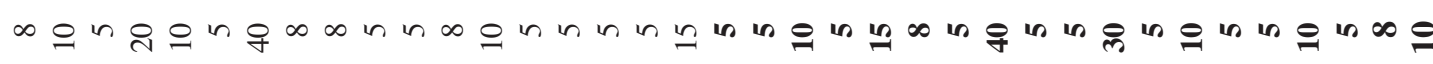

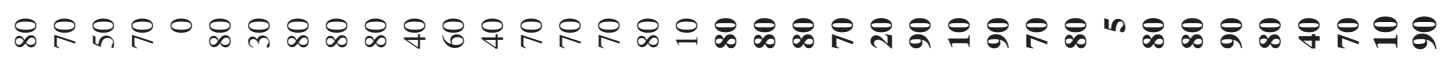
$\sqrt{20}$ $\mid \frac{\widehat{Q}}{\frac{c}{I}}$

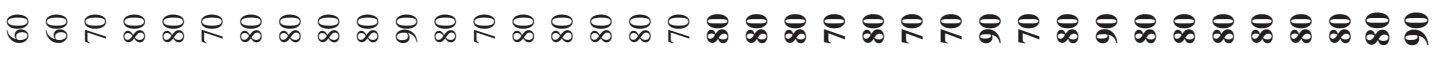

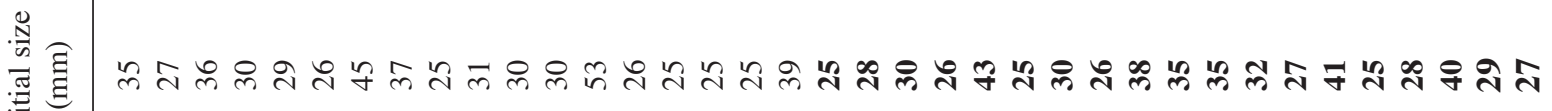
当

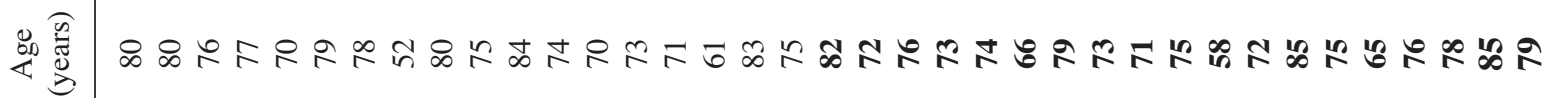

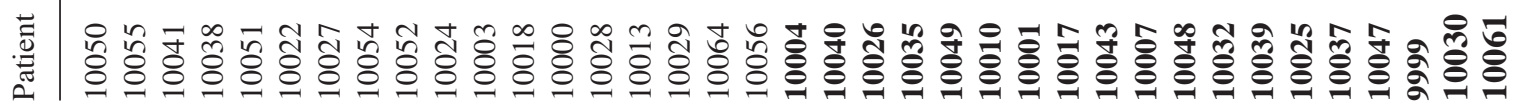


purpose of this study was to verify whether the K303R ER mutation is associated with response to treatment. Notably, no DNA extracted from the post-treatment biopsies demonstrated the alteration, neither in tumors responding to therapy, nor in non-responding tumors.

The absence of the K303R ER $\alpha$ mutation in our tumor cohort could be attributed to the relatively limited number of samples. Nevertheless, this alteration was either not detected in invasive cancer in four other studies (13-16), or was found with a low frequency (37 of 653 breast tumors, 5.7\%) (17). Herynk et al argued that dye-labeled terminator sequencing was not adequate for the detection of the A908G ER $\alpha$ mutation, and that the alteration was detected at a high frequency in invasive breast tumors using only primer extension sequencing (SNaPshot) (11). We attempted the same approach on an initial group of 10 DNA samples. Unfortunately, interpretation of the results was very difficult, as a very high background was present; therefore, dye-labeled terminator sequencing with a different forward primer was used. With this approach, very clean sequences and low background were obtained. Conway et al attributed inferior sensibility to automated sequencing due to suppression of peaks, particularly $\mathrm{G}$ following A (17). Thus, we used Big Dye terminators and sequenced in the two senses, where the mutated sequence transforms a T into a C. No mutation was able to be found.

An alternative explanation could be that the in vivo K303R $E R \alpha$ mutation has biological significance in only a subset of breast cancers, as hypothesized by Conway et al (17). In that study, mixed lobular/ductal tumors were more likely than ductal tumors to carry the K303R ER $\alpha$ mutation; no tumor in our cohort showed similar characteristics, as they were all lobular or ductal carcinomas. Moreover, K303R ER $\alpha$ mutationpositive breast cancer was significantly associated with longer duration and recent use of oral contraceptives (OCs) and OC use has been more strongly associated with the development of lobular and mixed lobular/ductal breast tumors $(22,23)$. In our cohort, all of our patients were post-menopausal, and 31 out of the $37(84 \%)$ were treated at an age older than 70 years; in Italy, the use of OCs was introduced in 1971, so it is likely that many of our patients never practiced their use.

\section{Acknowledgements}

We thank Dr Annalisa Lanza from Fondazione Maugeri for sample storage and delivery.

\section{References}

1. Chalbos D, Vignon F, Keydar I and Rochefort H: Estrogens stimulate cell proliferation and induce secretory proteins in a human breast cancer cell line (T47D). J Clin Endocrinol Metab 55: 276-283, 1982.

2. Russo $\mathrm{J}$ and Russo IH: The role of estrogen in the initiation of breast cancer. J Steroid Biochem Mol Biol 102: 89-96, 2006.

3. Beatson G: On the treatment of inoperable cases of carcinoma of the mamma: suggestions for a new method of treatment, with illustrative cases. Lancet 147: 101-107, 1986.

4. Smith IE and Dowsett M: Aromatase inhibitors in breast cancer. N Engl J Med 348: 2431-2442, 2003.

5. Osborne CK: Tamoxifen in the treatment of breast cancer. $\mathrm{N}$ Engl J Med 339: 1609-1618, 1998.

6. Allred DC, Mohsin SK and Fuqua SA: Histological and biological evolution of human premalignant breast disease. Endocr Relat Cancer 8: 47-61, 2001.
7. Elledge RM and Fuqua SAW: Estrogen and progesterone receptors. In: Diseases of the Breast. Harris JR, Lippman ME, Morrow M, et al (eds). Lippincott, Williams \& Wilkins, Philadelphia, pp471-488, 2000

8. Hopp TA, Weiss HL, Parra IS, Cui Y, Osborne CK and Fuqua SA: Low levels of estrogen receptor $\beta$ protein predict resistance to tamoxifen therapy in breast cancer. Clin Cancer Res 10: 7490-7499, 2004.

9. Pike MC, Spicer DV, Dahmoush L and Press MF: Estrogens, progestins, normal breast cell proliferation, and breast cancer risk. Epidemiol Rev 15: 17-35, 1993.

10. McGuire WL, Chamness GC and Fuqua SA: Estrogen receptor variants in clinical breast cancer. Mol Endocrinol 5: 1571-1577, 1991.

11. Herynk MH, Parra I, Cui Y, Beyer A, Wu MF, Hilsenbeck SG and Fuqua SA: Association between the estrogen receptor $\alpha$ A908G mutation and outcomes in invasive breast cancer. Clin Cancer Res 13: 3235-3243, 2007.

12. Fuqua SA, Wiltschke C, Zhang QX, Borg A, Castles CG, Friedrichs WE, Hopp T, Hilsenbeck S, Mohsin S, O'Connell P and Allred DC: A hypersensitive estrogen receptor- $\alpha$ mutation in premalignant breast lesions. Cancer Res 60: 4026-4029, 2000.

13. Tebbit CL, Bentley RC, Olson JA Jr and Marks JR: Estrogen receptor a (ESR1) mutant $\mathrm{A} 908 \mathrm{G}$ is not a common feature in benign and malignant proliferations of the breast. Genes Chromosomes Cancer 40: 51-54, 2004.

14. Tokunaga E, Kimura Y and Maehara Y: No hypersensitive estrogen receptor- $\alpha$ mutation (K303R) in Japanese breast carcinomas. Breast Cancer Res Treat 84: 289-292, 2004.

15. Davies MP, O'Neill PA, Innes H and Sibson DR: Hypersensitive K303R oestrogen receptor- $\alpha$ variant not found in invasive carcinomas. Breast Cancer Res 7: R113-R118, 2005.

16. Zhang Z, Yamashita H, Toyama T, Omoto Y, Sugiura H, Hara Y, Haruki N, Kobayashi $\mathrm{S}$ and Iwase $\mathrm{H}$ : Estrogen receptor $\alpha$ mutation (A-to-G transition at nucleotide 908) is not found in different types of breast lesions from Japanese women. Breast Cancer 10: 70-73, 2003.

17. Conway K, Parrish E, Edmiston SN, Tolbert D, Tse CK, Geradts J, Livasy CA, Singh H, Newman B and Millikan RC: The estrogen receptor- $\alpha$ A908G (K303R) mutation occurs at a low frequency in invasive breast tumors: results from a population-based study. Breast Cancer Res 7: R871-R880, 2005.

18. Cui Y, Zhang M, Pestell R, Curran EM, Welshons WV and Fuqua SA: Phosphorylation of estrogen receptor $\alpha$ blocks its acetylation and regulates estrogen sensitivity. Cancer Res 64: 9199-9208, 2004.

19. Giordano C, Cui Y, Barone I, Ando S, Mancini MA, Berno V and Fuqua SA: Growth factor-induced resistance to tamoxifen is associated with a mutation of estrogen receptor alpha and its phosphorylation at serine 305. Breast Cancer Res Treat 119: 71-85, 2010.

20. Therasse P, Arbuck SG, Eisenhauer EA, Wanders J, Kaplan RS, Rubinstein L, Verweij J, van Glabbeke M, van Oosterom AT, Christian MC and Gwyther SG: New guidelines to evaluate the response to treatment in solid tumors. European Organization for Research and Treatment of Cancer, National Cancer Institute of the United States, National Cancer Institute of Canada. J Natl Cancer Inst 92: 205-216, 2000.

21. Barone I, Cui Y, Herynk MH, Corona-Rodriguez A, Giordano C, Selever J, Beyer A, Andò S and Fuqua SA: Expression of the K303R estrogen receptor- $\alpha$ breast cancer mutation induces resistance to an aromatase inhibitor via addiction to the PI3K/Akt kinase pathway. Cancer Res 69: 4724-4732, 2009.

22. Conway K, Parrish E, Edmiston SN, Tolbert D and Tse CK: Risk factors for breast cancer characterized by the estrogen receptor alpha A908G (K303R) mutation. Breast Cancer Res 9: R36, 2007.

23. Li CI, Malone KE, Porter PL, Weiss NS and Tang MT: Reproductive and anthropometric factors in relation to the risk of lobular and ductal breast carcinoma among women 65-79 years of age. Int J Cancer 107: 647-651, 2003. 